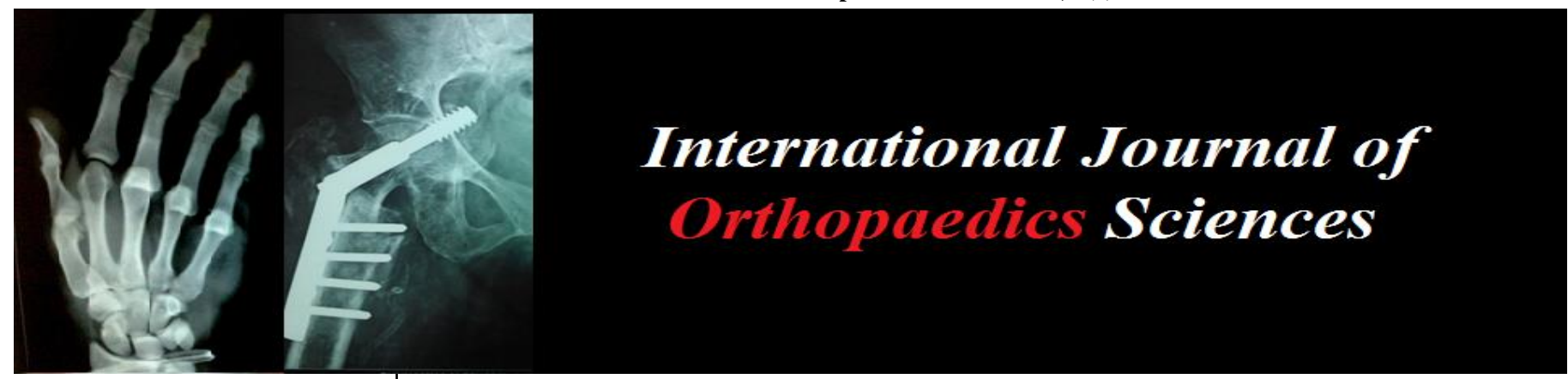

E-ISSN: 2395-1958

P-ISSN: 2706-6630

IJOS 2020; 6(3): 838-840

(C) 2020 IJOS

www.orthopaper.com

Received: 12-05-2020

Accepted: 23-06-2020

\section{Dr. Rasiq Rashid}

Junior Resident,

Department Of Orthopaedics,

VIMS \& RC, Karnataka, India

\section{Dr. Ambareesh}

Asst. Professor,

Department of Orthopaedics

VIMS \& RC Bengaluru,

Karnataka, India

\section{Dr. Hiranya Kumar S}

Prof. \& H.O.D Department of Orthopaedics VIMS \& RC

Bengaluru, Karnataka, India
Corresponding Author:

Dr. Rasiq Rashid

Junior Resident,

Department Of Orthopaedics,

VIMS \& RC, Karnataka, India

\title{
Isolated dislocation of talonavicular joint: A case report and a review of literature
}

\section{Rasiq Rashid, Ambareesh and Hiranya Kumar S}

DOI: https://doi.org/10.22271/ortho.2020.v6.i3m.2290

\section{Abstract}

Isolated talonavicular joint dislocation is very rare type of injury. A 21 year old man reported to our department with history of fall from height and landed on his feet. Post trauma, he complained of pain over his left foot and was unable to ambulate. On clinical examination his Left foot had diffuse swelling over dorsum. He was unable to do plantar flexion of his ankle. Neurovascular of left foot remained intact. $\mathrm{He}$ was treated by open reduction and K-wire fixation. At 12 weeks follow up foot was painless, stable with normal range of ankle and subtalar motion

Keywords: Medial swivel dislocation, subtalar-subluxation, isolated talonavicular dislocation

\section{Introduction}

- Isolated dislocation of talonavicular joint without associated subtalar joint dislocation or fracture of tarsal bones is rare. These injuries are caused by severe abduction or adduction force applied to the forefoot. Main and Jowett described a variant of subtalar dislocation termed as swivel injury ${ }^{[1]}$.

- This is usually caused by a high-energy mechanism such as a road traffic accident or a fall from a height ${ }^{[3]}$.

- Injuries are often compound in nature or 1 element of a polytraumatized patient. Consequently, the management is challenging, and the treatment is fraught with a high rate of disability, infection, and amputation ${ }^{[3,4]}$.

- The midtarsal joint, also referred to as the transverse tarsal joint and Chopart's joint, consists of the talonavicular and calcaneocuboid joints.

- This arthrodial joint which separates the hindfoot from the midfoot has received relatively little attention in the literature.

\section{Case Report}

A 21 year old man reported to our department with history of fall from height and landed on his feet. Post trauma, he complained of pain over his left foot and was unable to ambulate.

On clinical examination his Left foot had diffuse swelling over dorsum. He was unable to do plantarflexion of his ankle. Neurovascular of left foot remained intact.

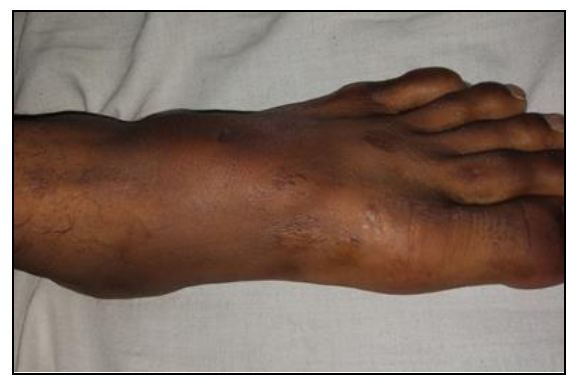

Fig 1: Showing clinical images of injured left foot with diffuse swelling over dorsum at the time of presentation

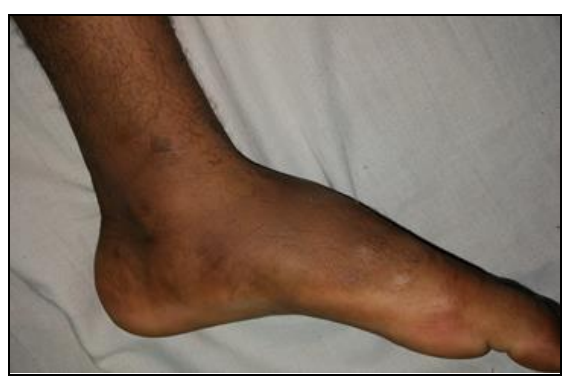

Fig 2: Showing clinical images of swollen and deformed left foot 
On radiographic examination Roengogram and Computed Tomography showed talonavicular dislocation with talar tuberosity chip fracture.

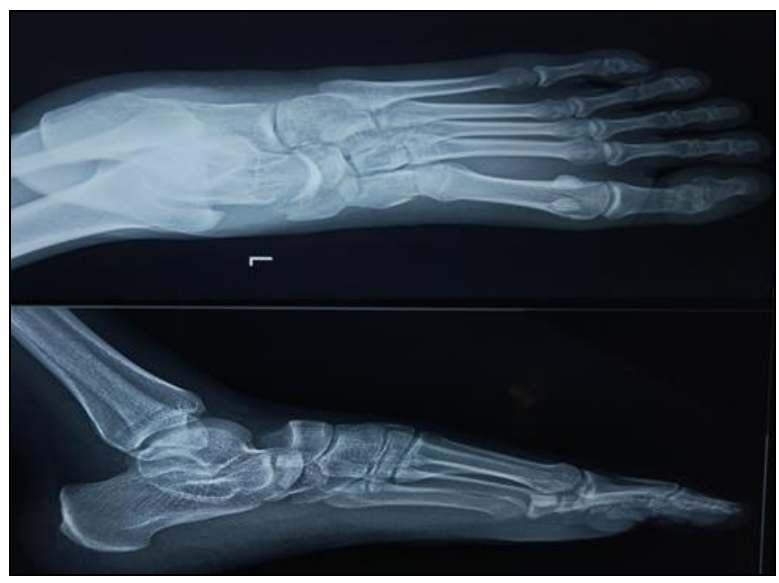

Fig 3: Preoperative radiographs anteroposterior and lateral view of left foot showing isolated talonanicular dislocation

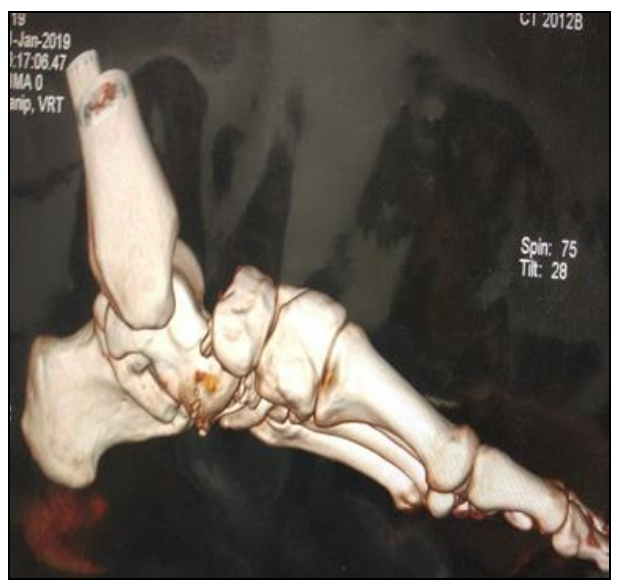

Fig 4: CT scan images of left foot showing isolated talonanicular dislocation with talar tuberosity chip fracture.
The patient was taken for closed reduction under spinal anaesthesia but an attempt to do closed reduction failed, Hence it was planned for open reduction and $\mathrm{K}$ wire fixation. Under tourniquet control, a $6 \mathrm{~cm}$ anteromedial longitudinal incision was made between extensor hallucis longus and extensor digitorum longus centering the talonavicular joint. Extensor hallucis longus tendon and dorsalis pedis artery were retracted medially, and extensor digitorum longus tendons were retracted laterally, exposing the dislocated talonavicular joint.

The talonavicular joint dislocation was reduced by traction and lateral rotation of the forefoot. The talonavicular joint was stabilized with 2-mm k-wires introduced from the dorsum of the foot transfixing the talonavicular joint. The wound was closed in layers.

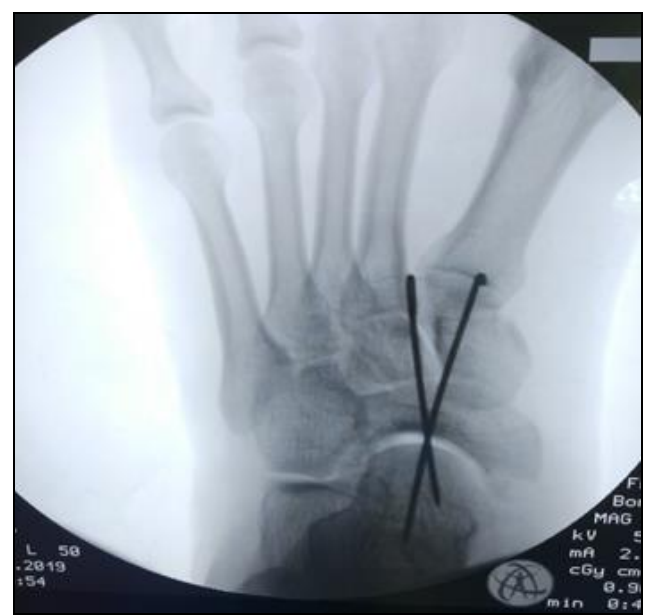

a)

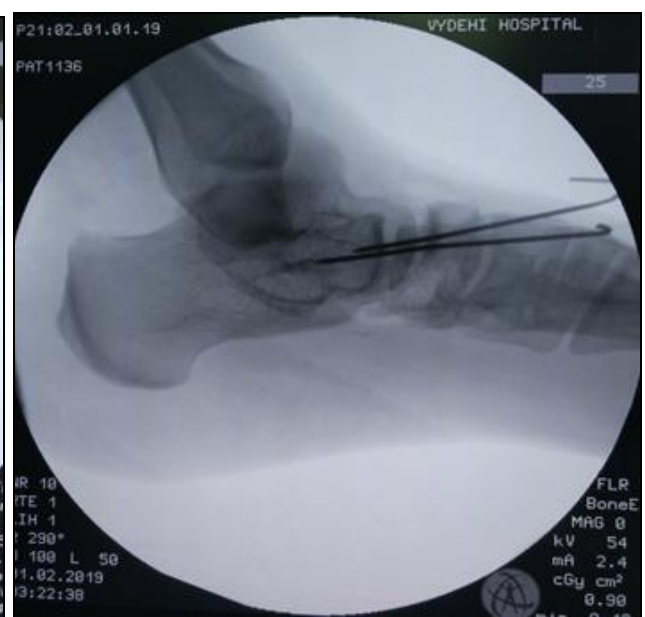

b)

Fig 5: Intraoperative anteroposterior (a) and lateral (b) radiographs of left foot showing congruent talanavicular, subtalar, and calcaneocuboid joints with $\mathrm{k}$-wires in situ.

Post operatively, patient was immobilized with below knee slab and kept non weight bearing for 6 week. After 6 weeks, $\mathrm{k}$-wires were removed, and weight-bearing was allowed progressively and returned to full weight-bearing after 9 weeks. Patient was back to normal activities after 12 weeks.

\section{Discussion}

Isolated talonavicular dislocation is rare. It represents complex plantar ligamentous structures injury ${ }^{[5]}$.

It is important to recognize this injury as early diagnosis and management favours good outcome. ${ }^{5}$ Anatomic reduction and stable fixation can be achieved using closed manual reduction or open reduction if close fails and percutaneous $\mathrm{k}$ wiring fixation ${ }^{[6]}$.

It is important to distinguish between medial subtalar dislocation and swivel dislocation of medial type.

Medial subtalar dislocation is reduced by traction and eversion, whereas swivel dislocation is reduced by traction and lateral rotation of foot.

In this case, closed reduction was not successful because of soft tissue interposition, and hence, open reduction and k-wire fixation was done with good clinical and functional outcome [6].

This case is presented because of its rarity, unusual mechanism of injury, and excellent outcome of treatment.

The midtarsal joint includes talonavicular and calcaneocuboid joints, which lie in a transverse plane across foot.

Main and Jowett ${ }^{[1]}$ classified midtarsal injuries according to direction of deforming force and displacement into five groups (medial, longitudinal compression, lateral, plantar, and 
crush) ${ }^{[1,2]}$. Medial and lateral midtarsal injuries are further divided into fracture, sprain, fracture subluxation or dislocation, and swivel dislocation ${ }^{[1]}$.

In the swivel injuries, the deforming force applied to the forefoot disrupts talonavicular joint, rotating the foot, causing rotatory subluxation of subtalar joint on the axis of intact interosseous talocalcaneal ligament. In medial swivel injuries, talonavicular joint dislocates medially rotating foot medially, whereas the calcaneocuboid joint is intact. Lateral swivel injuries, dislocates talonavicular joint laterally and rotates foot laterally. It is associated with impacted fracture of calcaneocuboid joint (nut cracker fracture) ${ }^{[7]}$.

Swivel injuries differ from subtalar joint dislocation in that the deforming force probably falls more anterior to that which produces subtalar and ankle injuries ${ }^{[1,2]}$. The talocalcaneal interosseous ligament is intact.

\section{References}

1. Main BJ, Jowett RL. Injuries to the midtarsal joint. J Bone Joint Surg Br. 1975; 57:89-97.

2. Kenwright J, Taylor RG: Major injuries of the talus. J Bone Joint Surg. 1970; 52:38-48.

3. Ricci WM, Bellabarra C, Sanders R. Transcalcaneal navicular dislocation. J Bone Joint Surg. 2002; 84:557561.

4. Coltart WD. Aviator's astragalus. J Bone Joint Surg Br. 1952; 34:545-566.

5. Complex Talonavicular Fracture Dislocation: A case report J. Terrence Jose Jerome, Mathew Varghese et el The Foot and Ankle Online Journal, 2010, 3(9).

6. Verhaar JA. Recurrent medial swivel dislocation of the foot. J Bone Joint Surg Br. 1990; 72:154-5.

7. Pillai A, Chakrabarti D, Hadidi M. Lateral swivel dislocation of the talo-navicular joint. Foot Ankle Surg. 2006; 12:39-41. 